\title{
Influence of Geogebra on Students' Achievement in Geometric Transformations and Attitude towards Learning Mathematics with Technology
}

\author{
DARREN BWALYA \\ The Copperbelt University
}

\begin{abstract}
The purpose of this study was to investigate the influence of GeoGebra on students' achievement in geometric transformations and attitudes toward learning mathematics through technology. In the mathematics classroom, the use of GeoGebra can help students and teachers to explore the mathematical ideas and concepts and the association of these ideas and concepts with real life examples, thus resulting in permanent and effective learning in mathematics and higher mathematics achievement (Doktoroğlu, 2013; Saha, Ayub \& Tarmizi, 2010; Mwingirwa, 2016; Leong, 2013; Leong \& Noorbaizura, 2013; Furkan, Zengin \& Kutluca, 2012; Zengin, 2011; Mercan, 2012; Bilgici and Selçik, 2011; Akgül,2014). Two theories, multiple representations theory (Bruner, 1966) and social constructivism (Vygotsky, 1978) which is anchored on two twin concepts of Zone of Proximal Development (ZPD) and scaffolding formed the framework of this thesis. The sample consisted of 66 Grade twelve students at St Marcellin's secondary School in Kalulushi. This study followed a pre-test post-test research design. Achievement in geometric transformations was measured using GTPreT and GTPT while attitude toward learning mathematics through technology was measured using MTAS items. The intervention was teaching geometric transformations with GeoGebra in contrast to using traditional teaching methods in the control group.After the intervention, it was found that there was a statistically significant difference in achievement in GTPT in favor of the experimental group. The researcher concluded that GeoGebra may be an effective tool for teaching geometric transformations to students in Zambian Secondary Schools. It was also concluded that GeoGebra benefits both male and female students and therefore it is useful in bridging the gap between the genders in the learning of mathematics. The study will add to the current knowledge in the teaching of mathematics in the Zambian curriculum and hence improve performance.
\end{abstract}

Keywords: GeoGebra, achievement, attitude, geometric transformations, technology

DOI: $10.7176 / \mathrm{JEP} / 10-13-04$

Publication date:May $31^{\text {st }} 2019$

\subsection{Introduction of the study}

Today we live in a technology era and as such it is inevitable that technology affects how we teach and how we learn. Due to many research studies for new approaches to the process of teaching-learning, that have been conducted for many years, new supportive techniques that enable effective teaching and learning have been developed. One of these techniques is the integration of technology into the education field. GeoGebra is one of the dynamic geometry software that has been integrated in mathematics education. Many research studies show that GeoGebra is useful as a supportive tool in the learning and teaching of mathematics. GeoGebra shows positive impact on students'engagement (http://engagementjdw.webs.com/geogebra.htm); increase the amount of students' interactions with teachers; increase achievement in geometry, transformations and trigonometry; increase test scores; and benefit students who struggle with visualisation. In the mathematics classroom, the use of GeoGebra can help students and teachers to explore the mathematical ideas and concepts and the association of these ideas and concepts with real life examples, thus resulting in permanent and effective learning in mathematics and higher mathematics achievement (Doktoroğlu, 2013; Saha, Ayub \& Tarmizi, 2010; Mwingirwa, 2016; Leong, 2013; Leong \& Noorbaizura, 2013; Furkan, Zengin \& Kutluca, 2012; Zengin, 2011; Mercan, 2012; Bilgici and Selçik, 2011; Akgül,2014).

According to National Council of Teachers of Mathematics (NCTM, 2000), which is world's largest association of mathematics teachers, the use of technology has been an essential tool for teaching and learning mathematics at all grade levels as it improves students' skills in decision making, reasoning and problem solving. The use of technology in mathematics education not only helps students construct their visual representations of mathematics ideas and concepts, summarise and analyse data, but also enables students to investigate every area of mathematics, such as geometry, algebra and statistics (NCTM, 2000). The National Council of Teachers of Mathematics (NCTM) considers technology as one of the six principles of school mathematics and states:

'Technology is essential in teaching and learning mathematics; it influences the mathematics that is taught and enhances students' learning.' (p. 11)

NCTM (2008) also remarks that the use of interactive geometry softwares, computer algebra systems, applets, interactive presentation devices, speed sheets and calculators have an important place for permanent and effective 
learning of mathematics. Besides (NCTM,2008) emhasises that use of technology in education is essential for teaching and learning of mathematics and therefore all schools should have necessary technological substructure and equipment for the active use of educational technologies in mathematics education.

One of the most useful and versatile DGS is GeoGebra which was selected as dynamic software for this study. GeoGebra software is equipped with features of both DGS and CAS. GeoGebra is a free mathematics software created by Markus Hohenwarter in 2001 for his master's thesis project at the University of Salzburg, Austria. This particular software has established its place as a popular tool that can be used at all levels from primary school to university (Akkaya, Tatar \& Kagızmanl1, 2011; Aktümen \& Kabaca, 2012; Hohenwarter \& Fuchs, 2004; Hohenwarter \& Jones, 2007; Hohenwarter \& Lavicza, 2007; Kutluca \& Zengin, 2011).

GeoGebra not only provides students with facilities to experiment the mathematical ideas and to associate mathematical concepts with the real life examples but also helps students to examine the relationship between algebraic and geometric concepts better. It can also be used in many ways in the teaching and learning of mathematics: for demonstration and visualisation, as a construction tool since it has the ability for constructing shapes; for investigation to discover mathematics because it can help to create a suitable atmosphere for learning; and for preparing teaching materials using it as a cooperation, communication and a representation tool (Hohenwarter \& Fuchs, 2004). The software can be used with students ranging from elementary level to university level beginning with simple constructions up to the integration of functions. Students can explore mathematics alone or in groups and the teacher tries to be a guide in the background, giving support where necessary. Researches indicate that GeoGebra has a positive effect on students' mathematics achievement in geometric transformations (Akgül, 2014; Mercan 2012; Sar1-Yahşi 2012; Vasquez, 2015).

Attitude towards mathematics, which refers to a student's self-reported enjoyment, interest and level of anxiety towards mathematics (Akgül, 2014), plays a crucial role in the learning and achievement in mathematics (Akgül, 2014). Therefore, investigating the effectiveness of the instruction using GeoGebra, which may establish a positive attitude towards learning mathematics, is important for students' mathematics learning and achievement.

Considering the above information, this research investigated the effectiveness of GeoGebra on Grade twelve (12) students' mathematics achievement in geometric transformations, attitude towards learning mathematics and technology and determined whether there is any difference between male and female students' achievement in geometric transformations taught using GeoGebra at St Marcellin's Secondary School.

\subsection{Background of the study}

The Government of the republic of Zambia through the Ministry of Education is working hard in finding ways of improving performance of students in schools. One way the Ministry of education (MOE) is doing this is by encouraging teachers to shift from teacher centered approaches to learner centered approaches such as ICT techniques which put learners at the heart of learning (Ministry of Education Teacher's Curriculum Implementation Guide, 2013, Ministry of Education and Japanese International Co-operation Agency (JICA, 2013).

Geometric transformations is one of the topics that are taught to Grade 12 students and feature almost every year in mathematics examinations prepared by Examinations Council of Zambia in Zambia. Learning geometric transformations help pupils improve logic, problem solving and deductive reasoning skills. Geometric transformations have many practical and daily applications. It is used in art, engineering, sports, cars, architecture and much more. Since geometric transformation deals with space and shapes, it is easy to see why it has many applications in the life of an average person as opposed to algebra or calculus, which are typically only used by those going into math-related fields.

\subsection{Statement of the problem}

Poor performance of students in mathematics has been of great concern to government and other stakeholders including teachers and parents. Geometric transformations are one of the topics which many students have difficulties with. According to chief examiners' reports (2011, 2012, 2013, 2014, 2015, 2016), most students fail to answer questions on most topics that come in the final examinations including geometric transformations. As a result of this, the trend in mathematics results has deteriorated in recent years.

For example, in 2012 Grade 12 final examinations, The Examinations Council of Zambia (ECZ) reported that 6600 students obtained $0 \%$ in mathematics paper one. The ECZ reported further that another 6843 students obtained $0 \%$ in paper two. The report also reviewed poor performance at Grade nine level where more than $15 \%$ of the 288933 students scored $0 \%$ in paper two in addition to $0.24 \%$ with the same marks in paper one. The mean performance in mathematics was $20.41 \%$. The report also revealed that students who obtained $0 \%$ did not master the concepts and skills tested in the syllabus.

In 2013 , the mean score for mathematics paper one was $29.4 \%$ while that of paper two was $24.1 \%$ giving a total of $26.5 \%$. In 2014, the mean score for mathematics paper one was $12.7 \%$ whilst paper two was $21.0 \%$ giving a total of $17.0 \%$. Additionally, examiners report highlighted that generally poor performance was recorded in 
mathematics, science and commerce. In 2015, performance in mathematics and science reduced. Mathematics and Science had the lowest mean scores with $17.4 \%$ and $17.65 \%$ respectively. Number of students obtaining Zero percent in mathematics increased from 12,076 in 2014 to 13,282 in 2015. One recommendation from examiners was that school administrators and teachers should ensure candidates are exposed to hands-on learning activities and therefore be able to relate theory to practice. In mathematics, the use of Dynamic geometry softwares such as GeoGebra can help in generating hands-on learning activities.

Table 1.2 Pass Rate (\%) in Mathematics in Zambia in selected years and from 2012 to 2015

\begin{tabular}{lllllllll}
\hline $\mathbf{1 9 9 9}$ & $\mathbf{2 0 0 1}$ & $\mathbf{2 0 0 3}$ & $\mathbf{2 0 0 6}$ & $\mathbf{2 0 0 8}$ & $\mathbf{2 0 1 2}$ & $\mathbf{2 0 1 3}$ & $\mathbf{2 0 1 4}$ & $\mathbf{2 0 1 5}$ \\
\hline 34.3 & 35.7 & 38.5 & 38.5 & 39.3 & 46.7 & 26.5 & 17.0 & 37.6 \\
\hline
\end{tabular}

Source: Examinations Council of Zambia

Although the performance of learners generally in mathematics and in particular in geometric transformations has been poor no study has been done at St Marcellin's Secondary School to determine whether GeoGebra can help in improving performance. Therefore there is a knowledge gap that needs to be addressed.

\subsection{Purpose of study}

The purpose of this study was to determine how GeoGebra influences students' achievement in geometric transformations, compared if there are any differences in achievement between male and female students taught using GeoGebra and analysed how GeoGebra influences students' attitude towards learning mathematics and technology. The findings of the study may shed light on the design of technology-supported learning environment and instructions from primary through to university level. Also, the information derived from this research can serve as foundations for curriculum developers at CDC for the development of mathematics curriculum.

\subsection{Research objectives}

This study was guided by the following objectives:

1. To determine how use of GeoGebra influences students' achievement in geometric transformations

2. To compare the achievement of male and female students in geometric transformations taught using GeoGebra

3. To analyse the influence of using GeoGebra to teach geometric transformations on students' attitude towards learning mathematics and technology

\subsection{Significance of the study}

Analyses of related literature indicate positive effects of using GeoGebra in terms of achievement in mathematics. In fact, even a study that was conducted in Zambia by Wakwinji (2011) indicated great potential of GeoGebra in enhancing achievement in mathematics. However, the effectiveness of GeoGebra is still needed to be investigated in Zambia. In other words, studies to investigate the effectiveness of GeoGebra on students' achievement in geometric transformations and attitude towards learning mathematics and technology are scarce in Zambia. Therefore, this study will contribute to the mathematics education literature.

It is hoped that this study will provide insight on how teachers of mathematics in Zambia can organize lessons in dynamic learning environments through GeoGebra. Findings of this research can as well be used as a suggestion about technology use in mathematics classrooms. In this way, it can help students by providing them with permanent and effective learning of mathematics. Therefore, this study can contribute not only to the mathematics education literature, but also to the teacher education, education practice, curriculum development and educational policy making.

This research may also pave way for subsequent researches on incorporating technology as another learnercentered teaching method to add to the existing teaching methods in an effort to not only improve performance in mathematics but also to find an answer to the question "How do we teach mathematics better in Zambia?" Findings of this research may also be significant in validating the usage of dynamic geometry softwares such as GeoGebra in the teaching of mathematics in Zambia.

\subsection{Theoretical framework}

Multiple Representations (MR) theory and the constructivist theory of social interaction for cognitive development whose main principles were anchored on the twin concepts of Zone of Proximal Development (ZPD) and Scaffolding formed the framework for this thesis. Jerome Bruner's work on representations has been interpreted as MR theory in mathematics education. The theory is useful in teaching mathematics which is primarily conceptual, as it begins with a concrete representation and progresses to a more abstract one. Initially, the use of manipulatives in the enactive stage is a great way to hook students who may not be particularly interested in the topic.

MR theory is believed by mathematics researchers to bring about motivation among students. Some representations, such as pictures, videos and manipulatives can motivate students because of their richness, possibilities of play, technologies involved or connections with interesting area of life (Hagarty \& Kozhevinikov, 
1999). Tasks that involve multiple representations can sustain intrinsic motivation in mathematics by supporting higher-order thinking and problem solving.

This study was also conducted based upon the constructivist theory of social interaction for cognitive development. The main principles were anchored on the twin concepts of ZPD and scaffolding. The ZPD is the difference between what a learner can do without help and what he or she can do with help (Penguin dictionary of psychology, 2009). Lev Vygotsky viewed interaction with peers as an effective way of developing skills and strategies. He suggested that teachers should use cooperative learning exercises where less competent children develop with help from more skillful peers - within the zone of proximal development. He believed that when a student is in the ZPD for a particular task, providing the appropriate assistance will give the student enough of the boost to achieve the task.

Scaffolding is a process through which a teacher or a more competent peer helps the student in his or her ZPD as necessary and tappers off this aid as it becomes unnecessary, much as a scaffold is removed from a building after construction is completed. Scaffolding is the way the more knowledgeable other guide's the child's learning via focused questions and positive interactions, (Morgan, 2009).

In this study, GeoGebra software basically acted as the primary scaffold in assisting and guiding the students to reach their ZPD. The students worked in pairs to construct diagrams and make observations based on the transformations. Students formed their own interpretations through shared understanding with the guidance of GeoGebra -where they were able to explore and visualise on their own. On top of that, the teacher and more competent students also played a part in the scaffolding process. The teacher gave instructional intervention at the beginning of the lessons to introduce the software tools to enable the students to work in pairs on their own using the step-by-step guide without the teacher's assistance. The teacher's role here was more of a facilitator which encouraged students to actively participate in the lesson and make significant connections.

Social interactions between students gave them opportunities to guide one another to reach a level of shared understanding. Here the higher ability students played a big role in helping the lower ability students to reach their ZPD. The higher ability students also benefited through the new ideas and views of their peers.

Students were also placed in groups of two to work on various transformations. They worked hand-in-hand assisting each other in performing transformations and making conclusions based on their findings. Vygotsky's views are closely related to this learning environment where he emphasized that social interaction and cultural environment contribute to cognitive development. However, this must take place within the zone of the individual's potential development. Students were placed in groups where the scaffolding process took place for them to perform transformations based on what they already knew and with the help accepted from their peers when needed. In this environment, the teacher acted as a facilitator. This manner of learning enhances critical thinking skills as students contribute ideas and views to reach a common understanding. However, this process was closely monitored by the teacher who was also the researcher to ensure a balance in terms of input from both group members. Here the higher ability students played a bigger role in helping the lower ability students reach their ZPD. GeoGebra gave the students an opportunity for peer interaction to enhance understanding and visualisation of the concepts on geometric transformations.

\subsection{Definitions of terms}

Dynamic Geometry Software (DGS) refers to the family of software that assists teachers and students to teach/learn the relations between geometrical behaviors and shapes (Aktümen, Horzum, Yildiz \& Ceylan, 2011).

Computer Algebra System (CAS) refers to the family of software that allows teachers and students to do symbolic and algebraic operations in mathematics in a simpler and easier way (Kabaca, 2006).

GeoGebra is a free and user-friendly mathematics software, which include features of DGS and CAS and has been translated into more than 50 languages. The software can be used from primary school through to university level. GeoGebra brings together geometry, algebra, spreadsheets, graphing, statistics and calculus (GeoGebra Tube, 2016).

Traditional methods refer to teacher-centered, textbook-based teaching methods. Traditional teaching methods include teaching through lectures, note-taking, questions and exercises. In traditional methods, the teacher acts as a knowledge transmitter and sometimes asks questions to the students. Rules, definitions, strategies and generalisations related to the topic are given first, and then examples are provided. The students are passive listeners and note-takers in this learning environment (Duatepe, 2004 in Akgül, 2014). In this study, the control group students were taught with traditional teaching methods.

Achievement is defined as "something accomplished successfully, especially by means of exertion, skill, practice or perseverance" (Thorndike \& Barnhart 1993, P. 46 in Akgül, 2014, P. 12). In this study, achievement means the total measurement of scores of GTPreT and GTPT. In other words, achievement is what GTPreT and GTPT measures.

Attitude is defined as "those beliefs formed from a combination of experiences measured in the domains of mathematics" (Capro, 2000, P. 8 in Akgül, 2014, P. 13). In this study, attitude means the total measurement of the 
scores of attitude towards mathematics scale. In other words, is what the MTAS measures.

Attitude towards mathematics and technology refers to students' self-reported enjoyment, interest and level of anxiety towards learning mathematics with technology (Pilli, 2008, in Akgül, 2014).

Geometric Transformations is defined as "a subset of geometry in which students learn to identify and illustrate movement of shapes in two and three dimensions. The four types of movement are slides (translations, as when a figure is moved on a page), flips (reflections that is when a figure is turned over in three dimensions), turns (rotations, when a figure is rotated $90^{\circ}$ without being flipped).” (Kirby \& Boutler, 1999, P. 285 in Akgül, 2014) and enlargement.

\subsection{Research Design}

In this study, pre-test post-test randomized group design was used to determine the influence of GeoGebra software on students' achievement in geometric transformations and their attitudes towards learning mathematics with technology. The participants of the study were randomly divided into two classes as an experimental and control groups by the researcher. In order to correct for any possible difference in their ability and knowledge before the intervention, both groups were given the Geometric Transformations Pre-Test (GTPreT) along with the Mathematics and Technology Attitude Scale (MTAS). Following the pre-test, geometric transformations were taught to the experimental group using GeoGebra while control group were taught using traditional methods. The teaching of both groups was done by the researcher. This was done concurrently for both groups. After the conclusion of the teaching process, the Geometric Transformations Post Test (GTPT) was applied and the same survey that was applied in the pre-test stage was given as post-test.

Table 3.1 A summary of research design

\begin{tabular}{lllc}
\hline Group & Pre-tests & Intervention & Post-tests \\
\hline Experimental & GTPreT & Teaching with & GTPT \\
& MTAS & GeoGebra & MTAS \\
Control & GTPreT & Teaching with & GTPT \\
& MTAS & Traditional methods & MTAS \\
\hline
\end{tabular}

\subsection{Research Instruments/ Tools}

The researcher used a Geometric Transformations Pre-Test (GTPreT), Geometric Transformations Post Test (GTPT) and Mathematics and Technology Attitude Scale (MTAS) as instruments for data collection.

\subsubsection{Geometric Transformation Pre-Test (GTPreT)}

This was an 8-item pre-test that was constructed by the researcher based on Zambian mathematics syllabus under geometric transformations. The test covered areas of knowledge, comprehension and application levels.

\subsubsection{Geometric Transformations Post Test (GTPT)}

This was an 11-item post-test that was constructed by the researcher based on Zambian mathematics syllabus under geometric transformations. The test covered areas of knowledge, comprehension and application levels. This test was given to both experimental and control groups after teaching geometric transformations.

\subsubsection{The Mathematics and Technology Attitudes Scale (MTAS)}

The mathematics and technology attitudes scale (MTAS) developed by Dr Pierce, Stacey and Barkatsas (2007) was used to examine the influence of GeoGebra software on students' attitudes towards learning mathematics with technology. The survey has five sub-scales: Behavioral engagement (BE), Affective engagement (AE), Attitude to learning mathematics with technology (MT), Confidence with technology (CT) and Mathematical confidence (MC).

A 5-point Likert -type with strongly agree to strongly disagree responses was used for four sub-scales AE, MT, CT and MC. For the sub-scale BE a similar format - nearly always, usually, about half of a time, occasionally, hardly ever was used. All the 5 sub-scales had scores from 1 to 5 and the average was computed based on the responses within each factor.

\subsection{Pilot study}

Pilot study was conducted to test the research methodology and data collection instruments. Before the actual pilot study, the instruments were tested on 40 Grade 12 students at Kalulushi secondary School and 40 Grade 11 students at St Marcellin's Secondary School. A simple random sampling procedure was used to select the participants for the pilot study. The purpose of the study was explained and instructions were given to the respondents. Pilot study was done on 60 students of Chavuma Secondary School (School not participating in the study but within Kalulushi). Pilot study gave the researcher good information about problems in the experiment. Statements that were not clear, corrections were made to ensure that the statements are clear for the respondents to answer them correctly. 


\subsection{Sample and sampling techniques}

The participants were male and female grade 12 students. Out of 80 grade 12 students only 66 participated in the study instead of 67 as calculated from the sample size calculator on https://www.surveymonkey.com $/ \mathrm{mp} / \mathrm{sample-}$ size-calculator using a confidence level of $95 \%$ and a margin of error of $5 \%$. This represented a return rate of $98.51 \%$. Sampling was randomly done. One class of 33 students was assigned to experimental group A and the other class of 33 was assigned to control group B.

Table 3.5 Gender distribution of participants

\begin{tabular}{|c|c|c|c|}
\hline & $\begin{array}{l}\text { Experimental } \\
\text { Group }\end{array}$ & $\begin{array}{l}\text { Control } \\
\text { Group }\end{array}$ & Total \\
\hline Male & 17 & 15 & 32 \\
\hline Female & 16 & 18 & 34 \\
\hline Total & 33 & 33 & 66 \\
\hline
\end{tabular}

\subsection{Data collection procedure}

Two instruments GTPreT and MTAS were used during pre-test period. After the pre-test, geometric transformations were taught with two different methods. The researcher taught geometric transformations by using GeoGebra to the experimental group. Students in the control group were taught geometric transformations using traditional teaching methods. Before the intervention period, the researcher prepared two lesson plans. The first lesson plan involved teaching with GeoGebra while the second lesson plan was prepared using the traditional methods. After the intervention, post-test was conducted using GTPT and MTAS.

\subsection{Reliability and Validity of the Research Instruments}

Reliability is defined as the extent to which a questionnaire, test, observation or any measurement procedure produces the same results on repeated trials (Kothari, 2004). In other words, it is the stability or consistency of scores over time or across raters. In this study, the researcher ensured the measurement instruments used measured the true score by; first, testing the research instruments on 40 Grade 11 students at St Marcellin's Secondary School, second, testing the instruments on 40 Grade 12 students at Kalulushi Secondary School and third, piloting the study on 66 students at Chavuma Secondary School. The average mean scores on the item responses were found to have insignificant deviations.

Validity on the other hand is defined as the "the degree to which an instrument measures what it purports to measure" (Mugenda, 2008 p.256). Validity of data depends on the degree to which extraneous variables have been controlled in the study to ensure that the change observed in the dependent variable is actually as the result of the treatment. Therefore, as evidence of validity, the researcher used the followings; (a) a pilot study, (b) views of mathematics teachers examiners from outside the school where the study was conducted and (c) views of mathematics teachers examiners from within the school where the study was conducted.

\subsection{Scope of the Study}

The study was limited to male and female Grade twelve students of St Marcellin's Secondary School. Although there are many computer applications and softwares that can be used to teach mathematics, the study focused on GeoGebra only and how it is used to enhance achievement in geometric transformations. In addition, the study focused on geometric transformations that are taught at secondary school level in Zambia. Therefore, the generalisations made in the conclusion are limited to mathematics at secondary school level only.

\subsection{Intervention}

For the intervention, geometric transformations were planned to be taught in GeoGebra supported environment (dynamic graphs) to the experimental group. The teacher was the researcher. Traditional teaching methods were used by the researcher in the control group class (using pencil and graph papers). Before the intervention, the researcher prepared two lesson plans. Each lesson plan contained four different transformations; translation, reflection, rotation and enlargement.

\subsection{Activities during lesson periods}

GeoGebra software including basic tools was introduced to students in the experimental group in order to familiarize them with the software. The researcher had already downloaded GeoGebra software and installed it in advance on computers in the computer lab of the school. The disc were GeoGebra software was saved was also given to experimental students in order for them to install it on their home computers for practice after school. Furthermore, the official GeoGebra website (www.geogebra.com) was given to students in order for them to download it on their own and to check the latest information about GeoGebra. This introduction lasted for about 20 minutes and the students liked the software since it was user friendly. During the lesson discussions, the researcher and experimental students created GeoGebra applets on translation, reflection, rotation and enlargement. 
The diagram below shows some of the transformations which students performed.

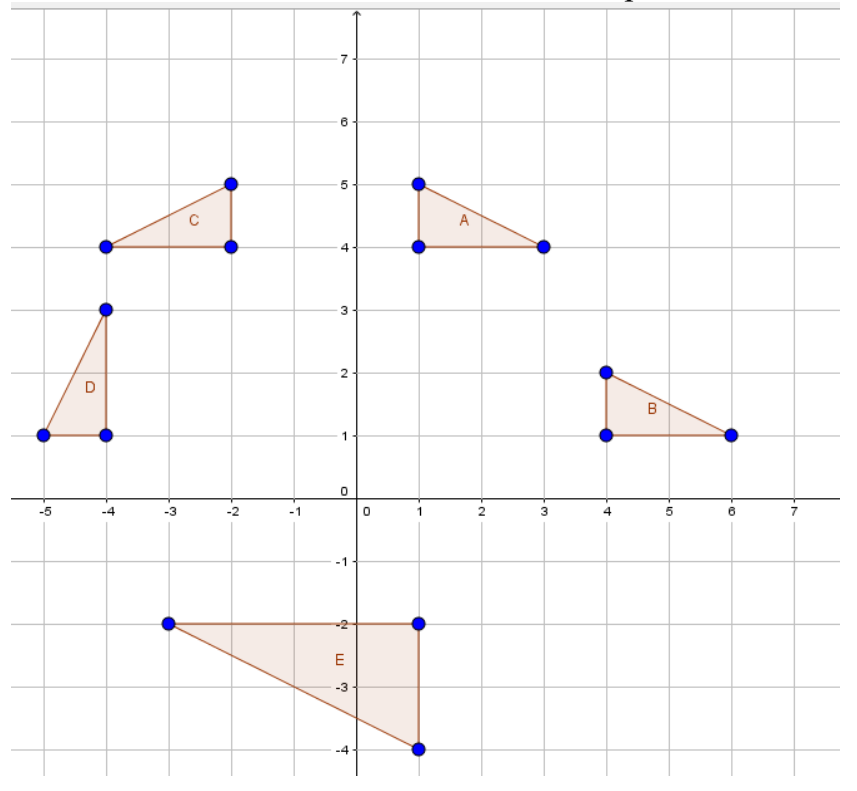

\subsection{Data Analysis procedure}

First, data were explored and analysed in terms of normality and outliers by using the statistics software SPSS version 21 . Normality of the data was examined in terms of the histograms, standard normal curves and p-p plots. Outliers were examined by using box plots. No outliers or missing scores were detected.

Second, descriptive statistics were used to analyse the data in order to have a better understanding of how the participants performed in both GTPreT and GTPT on average.

Third, to answer the research questions:

(a) Independent samples t-test statistics were conducted for GTPreT and GTPT scores of both groups

(b) Independent samples t-test statistics was conducted to determine whether there

was statistically significant post-test score differences on average between male and female students within the experimental group

(c) In order to determine whether there was a statistically significant effect of the intervention on the students' attitude towards learning mathematics with technology, independent samples t-tests were conducted, in each sub-scale, for MTAS pre-test and post-test scores to find the size of the impact for control and experimental groups

\subsection{Ethical Considerations}

Before undertaking this study, the researcher sought consent from all the participants to take part in the study. The researcher wrote an application letter to The District Education Board Secretary (DEBS) of Kalulushi to seek consent to do this study at the three Secondary Schools in Kalulushi. Further, the researcher wrote letters to The Head teachers of the three Secondary Schools, for seeking permission to undertake this study at their schools. From the individual respondents, the researcher sought consent in person for their willingness to participate in the study. It was explained to participants that they are free to withdraw from the study at any time and that their participation was solely voluntary. It was also made clear that the information they provided was purely for academic purposes and no one was requested to disclose his or her identity.

Moreover before using MTAS items, the researcher sought permission from Dr Pierce. To the researcher's advantage, permission was granted by Dr Pierce (see Appendix E showing how permission was given).

\section{DATA PRESENTATION, INTERPRETATION AND ANALYSIS}

\subsection{Data presentation}

Table 4.1 (a) Achievement of students in GTPreT

\begin{tabular}{clcc}
\hline Group & $\mathrm{n}$ & Mean score $(\%)$ & SD \\
\hline GTPreT Control & 33 & 34.09 & 12.89 \\
Experimental & 33 & 32.39 & 21.51 \\
Total & 66 & 33.24 & 17.62 \\
\hline
\end{tabular}


Table 4.1 (b) Achievement of students in GTPT

\begin{tabular}{lllcc}
\hline & Group & $\mathrm{n}$ & Mean score $(\%)$ & SD \\
\hline \multirow{2}{*}{ GTPT } & Control & 33 & 48.39 & 9.82 \\
& Experimental & 33 & 69.21 & 8.85 \\
& Total & 66 & 58.80 & 14.00 \\
\hline
\end{tabular}

Table 4.1 (c) Achievement of Experimental students in GTPT by gender

\begin{tabular}{lllcl}
\hline & Gender & $\mathrm{n}$ & Mean score (\%) & SD \\
\hline GTPT & Male & 18 & 68.33 & 8.53 \\
& Female & 15 & 70.27 & 9.40 \\
& Total & 33 & 69.29 & 8.85 \\
\hline
\end{tabular}

\subsection{Assumptions of t-tests}

According to Andy Field, before using t-tests to analyse data there are assumptions that need to hold (Field, 2013). The followings are the assumptions that need to hold before using t-tests:(i) Random, independent sampling from k populations; (ii) Normal population distributions; (iii) Equal variances within population.

This study ensured there was random and independent sampling during data collection and also ensured that the distribution of the data obtained was approximately normal. A normality test of p-p plots and histograms was done. P-P plot tests showed that the data in both GTPreT and GTPT were approximately normally distributed (see p-p plots on figure 16) and a visual inspection of the respective histograms (shown on figures 17 and 18) showed that the scores for GTPreT and GTPT were approximately normally distributed and hence fit for analysis using the t-tests.

Table 4.2 Levene's Test of Equality of Variances

\begin{tabular}{lcc}
\hline & \multicolumn{2}{c}{ Equal variances achieved } \\
\hline & F-value & P-value \\
GTPT & 0.016 & $0.900>\mathbf{0 . 0 5}$ \\
GTPT (by gender) & 0.943 & $0.339>\mathbf{0 . 0 5}$ \\
Post MT & 0.028 & $0.867>\mathbf{0 . 0 5}$ \\
\hline
\end{tabular}

Table 4.2 suggests that the assumption of homogeneity of variances was tenable because all the p values were greater than 0.05 . Therefore, it was assumed that the variances were roughly equal and as such the researcher read the test statistics in the row labeled equal variances assumed.

\subsection{Paired samples t-test statistics}

In order to determine whether there was a statistically significant improvement in both groups of students' achievement, paired samples t-test statistics were used. See Table 4.3 summarizing paired samples t-test statistics for both groups.

Table 4.3 Paired samples t-test statistics for both groups in GTPreT and GTPT

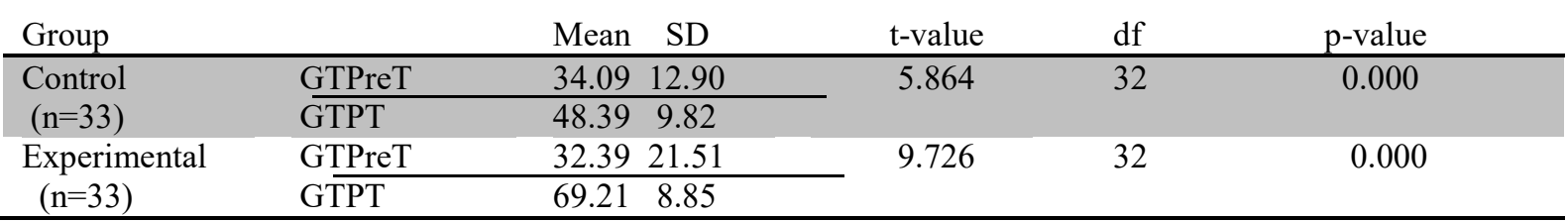

Table 4.3 indicates that statistically significant improvements were observed in both groups. Control group: $t=5.864, p=0.000<0.05$; Experimental group: $t=9.726, p=0.000<0.05$. These findings helped the researcher to reject the null hypothesis that there was no significant difference between GTPreT and GTPT scores for both groups.

\subsection{Influence of GeoGebra on Achievement}

In order to estimate the size of the impact of teaching with GeoGebra, independent samples t-test statistics were conducted for GTPreT and GTPT. See Table 4.4 
Table 4.4 Independent samples t-test for experimental and control groups in GTPreT and GTPT

\begin{tabular}{|c|c|c|c|c|c|c|}
\hline & Group $\mathrm{n}$ & Mean & SD & t-value & $\mathrm{df}$ & P-value \\
\hline \multirow[t]{2}{*}{ GTPreT } & CG 33 & 34.09 & 12.90 & 0.389 & 64 & 0.699 \\
\hline & $\begin{array}{ll}\mathrm{EG} & 33\end{array}$ & 32.39 & 21.51 & & & \\
\hline \multirow[t]{2}{*}{ GTPT } & CG 33 & 48.39 & 9.82 & 9.049 & 64 & 0.000 \\
\hline & $\overline{\mathrm{EG}} 333$ & 69.21 & 8.85 & & & \\
\hline
\end{tabular}

\section{DISCUSSIONS OF FINDINGS}

\subsection{Discussions of the major findings}

1. Students in the experimental group performed better than students in the control group on average in terms of scores in GTPT. When the independent samples t-test statistics was conducted for GTPT; there was a statistically significant difference between experimental group and control group $(p=0.000<0.005)$.

The explanation to this finding can be attributed to the design of the constructivist learning environment anchored on the concepts of the ZPD and scaffolds. GeoGebra acted as the scaffold which enabled students to reach their zone of proximal development (Vygotsky, 1978). This finding is supported by other studies done to determine the effects of a technology-rich environment on students learning (Dogan, 2010; Roberts, 2012; White, 2012; Praveen \& Leong, 2015). In this study, GeoGebra software basically acted as the primary scaffold in assisting and guiding the students to reach their ZPD. The students worked in pairs to construct diagrams and make observations based on the transformations. Students formed their own interpretations through shared understanding with the guidance of GeoGebra -where they were able to explore and visualise on their own. On top of that, the teacher and more competent students also played a part in the scaffolding process. In this study, it was also observed that GeoGebra based activities encouraged higher order thinking skills, and had a positive effect in motivating students toward learning.

2. Male and female students in the experimental group performed the same on

average in terms of scores in GTPT. When the independent samples t-test statistics

was conducted for students with respect to gender in the experimental group, there was no statistically significant difference between them $(\mathrm{p}=0.540>0.005)$.

The possible explanation to this finding can be attributed to the fact that both male and female students in the experimental group were exposed to the same technology-rich learning environment. GeoGebra gave both genders the opportunity to work on the concepts of geometric transformations through exploration and visualisation. GeoGebra encouraged a more interactive teacher-student or student-student interactional environment where everyone worked as a team to help and assist one another to reach the required learning objectives. GeoGebra acted as an important scaffold for both male and female students to bridge the ZPD. This finding revealed that GeoGebra learning environment gives equal chances of learning to both genders. This study also revealed that GeoGebra environment allows male and female students to learn mathematics at the same level and the result of this is a gain for both genders without bias. Thus, GeoGebra is nondiscriminatory on gender.

3. Students in the experimental group outperformed their peers in the control group on average in terms of scores in attitudes toward learning mathematics with technology (MT factor). When the independent samples t-test statistics was conducted for PostMT, there was a statistically significant difference between the experimental group and control group $(p=0.000<0.005)$.

\section{CONCLUSION AND RECOMMENDATIONS \\ 6.1 Conclusion}

The use of GeoGebra in mathematics teaching is a new area of study in Zambia and not much has been documented about it. This study concludes that GeoGebra is one sure solution to the poor performance in questions involving geometric transformations as it enhances understanding which is the key ingredient to good mathematics learning and hence improved performance in the area of geometric transformations at secondary school level. When it comes to gender equity, this study concludes that GeoGebra benefited both male and female students in learning geometric transformations since learning in the dynamic geometry environment did not discriminate against the students by gender. This study also concludes that GeoGebra enhances students' attitude toward learning mathematics with technology.

\subsection{Recommendations}

The results of this study showed that DGS-assisted Instruction using GeoGebra in the teaching of geometric transformations had significant effects on students' achievement and attitude toward learning mathematics with technology. Since mathematics is abstract in nature, GeoGebra as a dynamic geometry software helped students to better understand geometric transformations with concrete examples via visualisation in a dynamic learning environment. Besides, the students were active participants during lesson periods since the lessons prepared 
required active involvement of the students, such as making constructions, working on the activities, testing the mathematics ideas and hypotheses. Therefore, mathematics teachers in Zambia should integrate technological tools in their classrooms and they should know how to use dynamic geometry softwares adequately, effectively and systematically. This study may provide them with an example of this application to make them aware of the positive influence of dynamic geometry softwares on students' understanding of mathematics. In addition, mathematics teachers in Zambia should be provided with opportunities to develop effective teaching methods with the help of technology integration. They should be provided with in-service education courses on the integration of technology into mathematics teaching to help them gain the necessary competency for teaching with computers.

Furthermore, mathematics teachers in Zambia should be aware of different teaching methodologies, which can be applied in mathematics classrooms, and should pay special attention to the student-centered and technology enriched instruction methods. These methods can easily be applied and do not require much time and money and they provide conceptual understanding of mathematics and hence improved performance. Considering all the advantages dynamic geometry softwares provide, mathematics teachers in Zambia are recommended to use such softwares in their mathematics lessons while they are teaching different topics through longer time span to provide better understanding and permanent learning and to get better results in mathematics examinations.

As for teacher educators, universities such as UNZA and CBU, university colleges such as Mukuba and Nkrumah, and colleges of education such as Kitwe College of Education should include various courses to train prospective teachers for adequate and effective use of technological tools in mathematics teaching since such skills were needed and used intensively as the main part of the instruction given to the students by the researcher. Since mathematics teachers might not have time to develop their technological skills when they become in-service mathematics teachers, it is important for prospective teachers to experience the use of technology in mathematics teaching when they study at their respective institutions. Therefore, the prospective mathematics teachers should be equipped with necessary practical and theoretical knowledge and they should be competent in integration of technology into mathematics learning environment, such as teaching in GeoGebra enriched environments, or integrating other computer technologies into mathematics teaching, before they start to teach in secondary schools in Zambia as in-service mathematics teachers. Additionally, the use of these alternative teaching methods and supportive tools should be encouraged. In this way, teachers can make their mathematics teaching more effective so that students may be provided with a better understanding in mathematics and hence improved performance.

Curriculum developers at CDC in Zambia should pay special attention to the improved achievement in mathematics when taught using GeoGebra. Curriculum developers should also consider the effectiveness of GeoGebra on the development of attitude towards learning mathematics with technology and take into account the results of the present study during the curriculum development process. Moreover, the integration of dynamic mathematics softwares into mathematics curriculum and its importance should be highly emphasised rather than merely remaining as a recommendation.

\subsection{Recommendations for further research studies}

In the light of the findings of this study, the following are the recommendations for further research studies:

i. This study restricted itself to use of GeoGebra in the teaching and learning geometric transformations, there is need for further studies to be done to check if GeoGebra will be useful in other areas of mathematics such as algebra, calculus and statistics in Zambia

ii. Studies need to be done to establish the usefulness of GeoGebra in other levels of learning mathematics in Zambia; such as primary level and especially university level as it is seen that teaching mathematics at undergraduate level at Zambian universities is mainly teacher-centered that fosters procedural knowledge

iii. The quantitative research methodology was adopted in the present study. That is, the study was restricted with the analysis of quantitative data. Therefore, in order to provide in-depth insight into the effects of dynamic mathematics softwares on students' achievement and attitude towards learning mathematics with technology in Zambia, qualitative research methodologies, such as observations and interviews, are also recommended to be used.

\section{REFERENCES}

Akgül, M.B. (2014) The effect of using Dynamic geometry software on eight grade students' achievement in transformation geometry, geometric thinking and attitudes toward mathematics and technology.

Akkaya, A., Tatar, E., \& Kağımanlı, T. B. (2011). Using dynamic software in teaching of the symmetry in analytic geometry: The case of Geogebra. Procedia-Social and Behavioral Sciences, 15, 2540-2544.

Aktümen, M., \& Kabaca, T. (2012). Exploring the Mathematical Model of the Thumb Around Motion by GeoGebra. Technology, Knowledge and Learning, 17(3), 109-114.

Aktümen, M., Y1ld1z, A., Horzum, T., \& Ceylan, T. (2011). Elementary mathematics teachers' opinions about GeoGebra practicality in the lessons. Turkish Journal of Computer and Mathematics Education, 2(2), 103120. 
Doktoroğlu, R. (2013). The effects of teaching linear equations with dynamic mathematics software on seventh grade students' achievement (Unpublished Master's Thesis). Middle East Technical University, Turkey.

Examinations Council of Zambia (ECZ, 2010, 2011, 2012, 2013, 2014, 2015). Chief Examiners Reports, Lusaka, ECZ.

Field, A. (2013) Discovering statistics using IBM SPSS statistics $\left(4^{\text {th }}\right.$ ed $)$

GRZ (2011) Sixth National Development Plan. Lusaka Government Printers

Hohenwarter, M., \& Jones, K. (2007). Ways of linking geometry and algebra: the case of GeoGebra. In D. Küchemann (Ed), Proceedings of the British Society for Research into Learning Mathematics, 27(3), 126131.

Hohenwarter, M., \& Lavicza, Z. (2010). GeoGebra, its community and future. Paper presented at the Asian Technology Conference in Mathematics. Retrieved from http://www.unsam.edu.ar/

Hohenwarter, M., Hohenwarter, J., Kreis, Y., \& Lavicza, Z. (2008). Teaching and learning calculus with free dynamic mathematics software GeoGebra. Paper presented at the 11th International Congress on Mathematical Education. Monterrey, Nuevo Leon, Mexico.

Hohenwarter, M., \& Fuchs, K. (2004, May). Combination of dynamic geometry, algebra and calculus in the software system GeoGebra. ZDM Mathematics Education, 20(70), 1-5.

Kothari, C.R. (2004) Quantitative technique ( $3^{\text {rd }}$ ed) New Delhi, Vikas publishing house PVT Leong, K. E. (2013) Impact of Geometer's Sketchpad on Students' Achievement in graph functions. The Malaysian online journal of Education Technology, 1(2), 19-31

Leong, K. E. \& Noorbaizura, T (2013) Effect of students' achievement in Fractions using GeoGebra Vol. 16, 2013, PP 97-106

Leong, K. E. \& Preveen, S. (2015) Effectiveness of using GeoGebra on Students' understanding in learning circles, $1(4)$

Mercan M. (2012). The effects of use of a Dynamic Geometry Software Geogebra in teaching the subject of transformation geometry in seventh grade math class in a primary school on students' achievement and retention levels (Unpublished Master's Thesis). Gazi University, Turkey

Ministry of Education (MOE) and Japanese International Co-operation Agency (JICA) 2013, Lusaka, Ministry of Education

Ministry of Education. (2013) Teacher's Curriculum Implementation Guide, 2013 Lusaka, Ministry of Education

Mugenda, A.G. (2008). Social Science Research: Theory and Principles. Nairobi: Arts Press technology a review of literature. Technology, Pedagogy and Education, Vol. 9 (3) 319-342

Mwingirwa, I. M. (2016) Feasibility of using GeoGebra in the teaching and learning of Geometry concepts in Secondary Schools in Kajiado County, Kenya

National Council of teachers of Mathematics (2000) Principles and standards for school mathematics. Reston, VA: NCTM

National Council of teachers of Mathematics (2008) The role of Technology in the teaching and learning mathematics. Retrieved September 23, 2012, from http: //www.nctm.org/about/content.aspx?id=14233

Saha, R. A., Ayub, A. F. M., \& Tarmizi, R. A. (2010). The effects of GeoGebra on mathematics achievement: Enlightening coordinate geometry learning. International Conference on Mathematics Education Research, 8, 686-693.

Sar1-Yahşi, H. (2012). Primary 7th grade mathematics courses teaching the learning Area of the lower of dynamic geometry using the software of the rotation geometry with Geometer's Sketchpad and GeoGebra to compare the effects on students' success and permanency of learning (Unpublished Master's Thesis). Gazi University, Turkey.

Vasquez, E.D. (2015) Enhancing student achievement using GeoGebra in a Technology Rich Environment.

Wakwinji, I. (2011) Exploring how a workshop approach helps mathematics teachers start to develop technological pedagogical content knowledge.

Zengin, Y., Furkan, H. \& Kutluca, T. (2012) The effects of dynamic mathematics software GeoGebra on students' achievement in teaching of trigonometry. Procedia-Social and Behavioral Sciences, 31, 183-187

\section{DECLARATION}

\section{Student's declaration}

I, Darren Bwalya, do declare that this thesis represents my own work and that it has not in part or in whole been presented as material for award of any degree at this or any other university. Where other people's work has been borrowed including the internet, acknowledgement has been made and references cited.

Student's name: DARREN BWALYA

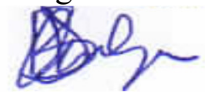

Computer Number: 15098917

Supervisor's declaration

I confirm that the work carried out by the candidate was under my supervision as supervisor at the Copperbelt 
University

Name: Ngambi R (Mr). School of Graduate Studies

Appendix E

MTAS permission (3)

To r.pierce@unimelb.edu.au

Hi Dr. Pierce

I am a Msc student at the Copperbelt University, Zambia. Am as well a mathematics teacher at a Govt school. In my masters research am studying the influence of GeoGebra on students' achievement and attitude towards learning maths with technology. I and my supervisor Dr. H. Mulenga agreed that your ' Mathematics and Technology Attitude Scale' is suitable and beneficial for my thesis. Therefore, i am kindly requesting for your permission to use your MTAS as part of my study. Your positive response will be appreciated.

Robyn Pierce <r.pierce@unimelb.edu.au>

To Darren Bwalya

CC Kaye Stacey

Dear Darren

Yes-we are happy for you to use this scale.

Best wishes for your research

Robyn

Sent from my iPad 